Research Article

\title{
Establishment of the Quantitative Analysis of Multiindex in Euphorbia lathyris by the Single Marker Method for Euphorbia lathyris Based on the Quality by Design Concept
}

\author{
Feng Xuehua $\mathbb{D}^{1},{ }^{1}$ Zhou Guangjiao $\mathbb{D}^{\mathbb{D}}{ }^{2}$ and Tao Ali $\mathbb{D}^{1}$ \\ ${ }^{1}$ College of Pharmacy, Anhui Xinhua University, Hefei 230088, China \\ ${ }^{2}$ Bozhou Chinese Medicine Institute, Anhui Academy of Chinese Medicine, Bozhou 236800, China \\ Correspondence should be addressed to Feng Xuehua; fengxuehua@axhu.edu.cn
}

Received 27 July 2021; Revised 27 August 2021; Accepted 1 September 2021; Published 17 September 2021

Academic Editor: Tien Duc Pham

Copyright (c) 2021 Feng Xuehua et al. This is an open access article distributed under the Creative Commons Attribution License, which permits unrestricted use, distribution, and reproduction in any medium, provided the original work is properly cited.

Methods. The influences of methanol proportion, flow rate, column temperature, and injection volume in the mobile phase on the chromatographic resolution of chromatographic peak of euphorbia factor L1 were experimentally studied via Plackett-Burman design, and the key analysis parameters were screened out; the key analysis parameters were optimized through the central composite design, and the chromatographic analysis conditions were established. Euphorbia factor L1 was taken as the internal reference to construct the relative correction factors for L3 and L4 relative to L1, and their contents were calculated, thus realizing the QAMS. Meanwhile, the euphorbia factor L3 and euphorbia factor L4 were determined using the external standard method, and the differences of values measured by the external standard method from the values predicted by the QAMS method were compared, in an effort to verify the accuracy and feasibility of the QAMS method. Results. The methanol proportion and column temperature in the mobile phase were the key analysis parameters $(P<0.05)$, and the chromatographic conditions were determined as follows. The methanol/water ratio, column temperature, detection wavelength, flow rate, and injection volume were $60: 40,30^{\circ} \mathrm{C}, 275 \mathrm{~nm}, 1.0 \mathrm{~mL} / \mathrm{min}$, and $10 \mu \mathrm{L}$, respectively. A total of 20 batches of samples were determined by the QAMS method and external standard method; the relative standard deviations (RSDs) of L3 and L4 determination results were less than 2.0\%, without any significant difference. Conclusion. The QbD-based QAMS method can be used to determine the contents of euphorbia factor L3 and euphorbia factor L4 in Euphorbia lathyris L., and it is accurate and feasible.

\section{Introduction}

The quality by design $(\mathrm{QbD})$ concept, which first appeared in Q8 released on the International Conference on the Harmonization of Requirements for Registration of Pharmaceuticals for Human Use (ICH), is defined as "a systematic research method with a predefined target, which highlights the understanding of products and processes and process control based on the reliable and scientific quality risk management" $[1,2]$. This method aims to strengthen the drug development and reach the expected product performance through the active design. In short, it means the pharmaceutical quality design. In 2005, the American pharmaceutical industry began to talk about QbD. Pfizer, Novartis, and Merck began to try to use QbD for drug development, registration, and market production. In 2006, food and drug administration officially launched $\mathrm{QbD}[3,4]$. The high-performance liquid chromatography (HPLC) plays a very important role in the pharmaceutical quality control by virtue of its fast, accurate, and reliable characteristics. By applying the QbD concept to the field of HPLC development, the concepts such as key quality attributes and key analysis parameters are introduced, and a reasonable analysis design scheme is acquired via risk assessment, experimental design, and statistical analysis $[5,6]$.

When it comes to the quantitative analysis of multicomponents by single marker (QAMS) method, one component in the target sample is taken as the internal reference, the relative correction factors between other components and this component are established, and the contents of 
other components are calculated through the relative correction factors, so as to realize the multicomponents synchronous determination [7-10]. Being able to effectively solve the problems of shortage of reference substances and high detection cost, this method is applicable to the multicomponents quality control of traditional Chinese medicinal materials $[11,12]$.

As a traditional Chinese medicinal material, Euphorbia lathyris L. is the dry mature seed of Euphorbia lathyris L. widely distributed or cultivated in Europe, North Africa, Central Asia, East Asia, South America, and North America [13]. Containing multiple chemical components such as diterpenoids, coumarins, steroids, and flavonoids, Euphorbia lathyris $\mathrm{L}$. is of extensive pharmacological activities, such as antitumor, antidiarrheic, and anti-inflammatory effects. The diterpenoid compounds separated out of Euphorbia lathyris L. exceed 20 species, and its diterpenoids has two frameworks: lathyrane and ingenane $[14,15]$, where the former mainly contains euphorbia factors L1, L2, L3, L8, and L9, and the latter mainly contains L4, L5, and L6 [16].

The QbD concept was applied to the HPLC method, the key factors influencing the chromatographic resolution of chromatographic peak were screened out through the Plackett-Burman design (PBD), the key analysis parameters were further optimized via the central composite design (CCD), and the QAMS method was established for the euphorbia factors L1, L3, and L4 in Euphorbia lathyris L.

\section{Materials and Methods}

2.1. Materials. Agilent 1290 Infinity II HPLC (all-duties pump; multisampler; diode array detector), Agilent UltiMate 3000 HPLC (LPG-3400A quaternion pump; PDA-3000 detector), Waters 2695 HPLC (2695 quaternary gradient pump; Waters 2487 dual wavelength UV detector), chromatographic column (Agilent ZORBAX SB-C18, $250 \mathrm{~mm} \times 4.6 \mathrm{~mm}, 5 \mu \mathrm{m}$; GL InertSustain C18, $250 \mathrm{~mm} \times 4.6 \mathrm{~mm}, 5 \mu \mathrm{m}$; Sagix Copsil C18, $250 \mathrm{~mm} \times 4.6 \mathrm{~mm}, 5 \mu \mathrm{m}$ ), TC-SY-1000 ultrasonic wave extractor (Beijing Tongde Venture Technology Co., Ltd.), CPA225D electronic scale (one hundred thousandth, Germany Sartorius Stedim Biotech), and XPR analytical balance (ten thousandth, Sweden Mettler-Toledo) were used.

Euphorbia factor L1, euphorbia factor L3, and euphorbia factor L4 reference substances (purchased from Baoji Herbest Biotech Co., Ltd., for the quantitative assay), and methanol (TCI AMERICA, chromatographic grade), acetonitrile (TCI AMERICA, chromatographic grade) were purchased, and the water used was ultrapure water.

2.2. Solution Preparation. Preparation of reference solution: accurately weighed the reference substances $10.08 \mathrm{mg}$ euphorbia factor L1, $10.05 \mathrm{mg}$ euphorbia factor L3, and $15.05 \mathrm{mg}$ euphorbia factor $\mathrm{L} 4$ in the same $100 \mathrm{~mL}$ volumetric flask, dissolved them with methanol and diluted to scale mark, and shook well to obtain a mixed reference solution containing $0.1008 \mathrm{mg}, 0.1005 \mathrm{mg}$, and $0.1505 \mathrm{mg}$ of euphorbia factor L1, euphorbia factor L3, and euphorbia factor L4 in every $1 \mathrm{~mL}$ of the sample solution.
Preparation of test solution: took appropriate amount of calamansi and pulverized it through No. 2 sieve to obtain medicinal powder. Took about $0.5 \mathrm{~g}$ of the powder, accurately weighed it, added $50 \mathrm{~mL}$ of $70 \%$ methanol aqueous solution, weighed, and ultrasonically extracted (power $250 \mathrm{~W}$, frequency $40 \mathrm{kHz}$ ) for $30 \mathrm{~min}$. Then, placed it at room temperature, weighed it, made up the lost weight with $70 \%$ methanol aqueous solution, shook well, filtered, and the filtrate was the test product.

2.3. HPLC Chromatographic Conditions. Agilent ZORBAX SB-C18 $(250 \mathrm{~mm} \times 4.6 \mathrm{~mm}, 5 \mu \mathrm{m})$ was used; detection wavelength was $275 \mathrm{~nm}$, column oven temperature was $20-30^{\circ} \mathrm{C}$, flow rate was $0.8-1.2 \mathrm{~mL} / \mathrm{min}$, and injection volume was $5-15 \mu \mathrm{L}$. Mobile phase was composed of a certain proportion of methanol and water, the methanol ratio was $60-70 \%$ in the mobile phase, and other conditions were determined according to the experimental design [17-19].

2.4. Plackett-Burman Design. According to the literature and preliminary experiments, taking the ratio of methanol in the mobile phase $(\mathrm{A})$, flow rate $(\mathrm{B})$, column temperature $(\mathrm{C})$, and sample injection volume (D) as the four factors to be investigated, the chromatographic resolution (Y) of the chromatographic peak of euphorbia factor L1 and euphorbia factor L4 were the key attribute quality [20].

2.5. PBD Experimental Program and Results. Screened the factors with certain risks through PBD and used Minitab to analyze the data [21]. The experimental program and results are given in Table 1, and the factor screening Pareto analysis is shown in Figure 1. The experimental results show that the methanol ratio (A) and column temperature $(\mathrm{C})$ in the mobile phase are significant for the quality of key attributes $(P<0.05)$, which are key analysis parameters, and other factors are noncritical analysis factors, so the flow rate and injection volume are set to $1.0 \mathrm{~mL} / \mathrm{min}$ and $10 \mu \mathrm{L}$, respectively.

\section{Results and Discussion}

3.1. Central Combination Design Optimization of Liquid Chromatography Conditions. Based on the PBD experiment, the two key analysis parameters of methanol ratio (X1) and column temperature (X2) in the mobile phase are optimized by CCD, and a mathematical model between it and key quality attributes was established [22], the experimental scheme and results are given in Table 2, and the analysis of variance is given in Table 3.

The $R^{2}$ of the $\mathrm{Y}$ model is 0.8102 , and the regression equation is $Y=+22.24149-0.54921 \mathrm{X} 1+0.036763 \mathrm{X} 2-$ $0.018600 \mathrm{X} 1 \mathrm{X} 2+7.15500 \mathrm{E}-003 * \mathrm{X} 1^{2}+0.0218553 * \mathrm{X} 2^{2}$.

From Table 3, it can be seen that the methanol ratio and column temperature have significant effects on the resolution of euphorbia factor L1 $(P<0.05)$, which is consistent with the experimental results obtained by $\mathrm{PBD}$. 
TABLE 1: PBD experimental program and results.

\begin{tabular}{lccccc}
\hline No. Methanol ratio A (\%) & $\begin{array}{c}\text { Flow rate B } \\
(\mathrm{mL} / \mathrm{min})\end{array}$ & Column temperature C $\left({ }^{\circ} \mathrm{C}\right)$ & Sample injection volume D $(\mu \mathrm{L})$ & Chromatographic resolution Y \\
\hline 1 & $60(-1)$ & $1.2(+1)$ & $20(-1)$ & $5(-1)$ & 1.62 \\
2 & $70(+1)$ & $1.2(+1)$ & $30(+1)$ & $5(-1)$ & 0.89 \\
3 & $60(-1)$ & $0.8(-1)$ & $30(+1)$ & $15(+1)$ & 1.53 \\
4 & $60(-1)$ & $1.2(+1)$ & $30(+1)$ & $15(+1)$ & 0.85 \\
5 & $60(-1)$ & $0.8(-1)$ & $20(-1)$ & $15(+1)$ & 3.23 \\
6 & $70(+1)$ & $0.8(-1)$ & $30(+1)$ & $15(+1)$ & 0.78 \\
7 & $70(+1)$ & $1.2(+1)$ & $20(-1)$ & $5(+1)$ & 1.45 \\
8 & $70(+1)$ & $0.8(-1)$ & $20(-1)$ & $5(-1)$ & 2.88 \\
9 & $70(+1)$ & $0.8(-1)$ & $30(+1)$ & $5(-1)$ & 0.91 \\
10 & $60(-1)$ & $0.8(-1)$ & $20(-1)$ & $15(+1)$ & 3.12 \\
11 & $70(+1)$ & $1.2(+1)$ & $20(-1)$ & $5(-1)$ & 0.86 \\
12 & $60(-1)$ & $1.2(+1)$ & $30(+1)$ & 1.94 \\
\hline
\end{tabular}

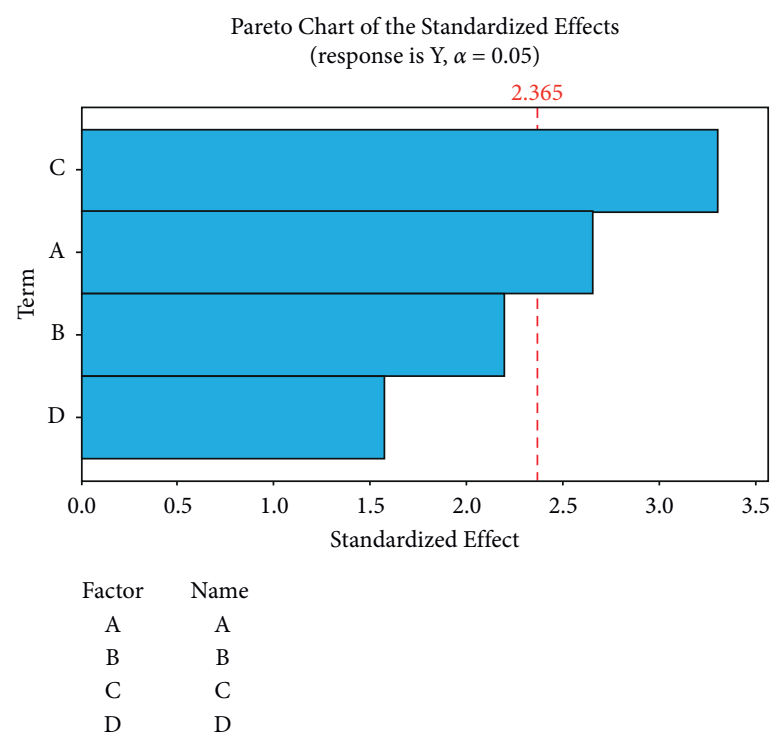

Figure 1: Analysis chart of factor screening Pareto.

TABLE 2: CCD experimental program and response value.

\begin{tabular}{lccc}
\hline No. & Methanol ratio X1 $(\%)$ & Column temperature X2 $\left({ }^{\circ} \mathrm{C}\right)$ & Chromatographic resolution Y \\
\hline 1 & $65(0)$ & $25(0)$ & 1.56 \\
2 & $65(0)$ & $25(0)$ & 1.12 \\
3 & $65(0)$ & $25(0)$ & 0.98 \\
4 & $72.07(1.414)$ & $25(0)$ & 1.33 \\
5 & $65(0)$ & $17.93(-1.414)$ & 3.19 \\
6 & $65(0)$ & $25(0)$ & 0.86 \\
7 & $65(0)$ & $25(0)$ & 1.11 \\
8 & $60(-1)$ & $20(-1)$ & 1.87 \\
9 & $65(0)$ & $32.07(1.414)$ & 1.96 \\
10 & $60(-1)$ & $30(+1)$ & 2.08 \\
11 & $70(+1)$ & $20(-1)$ & 1.84 \\
12 & $57.93(-1.414)$ & $25(0)$ & 2.35 \\
13 & $70(+1)$ & $30(+1)$ & 0.19
\end{tabular}

3.2. Condition Optimization and Prediction. The contour plots and response surface plots of each factor to the degree of separation are shown in Figures 2 and 3.
Using Design-Expert.8.0.6 software for derivation, it can be obtained that when the methanol ratio is $60 \%$ and the column temperature is $30^{\circ} \mathrm{C}$, the resolution can reach 2.33 . 


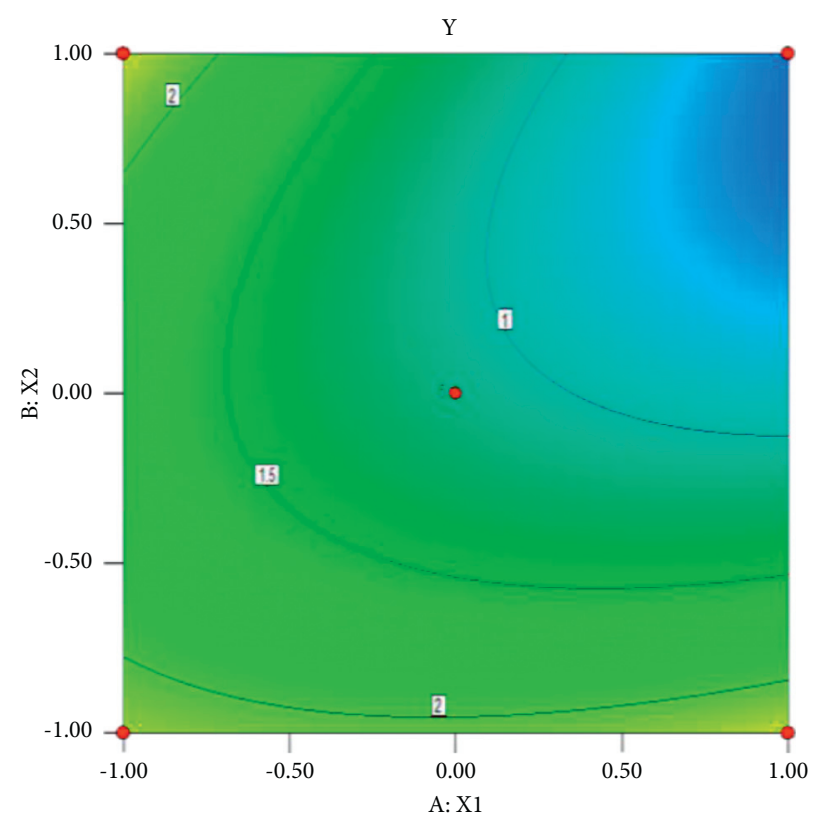

Figure 2: Contour plot of the effect of methanol ratio and column temperature on resolution.

TABLE 3: CCD Analysis of variance.

\begin{tabular}{|c|c|c|c|c|c|c|}
\hline Type & SS (sum of squares) & MS (mean square) & $F$ value & $P$ value $($ prob $>F)$ & Df & Significance \\
\hline Model & 5.7 & 1.14 & 5.97 & 0.0182 & 5 & Remarkable \\
\hline $\mathrm{X} 1$ & 1.41 & 1.41 & 7.41 & 0.0292 & 1 & Remarkable \\
\hline $\mathrm{X} 2$ & 1.26 & 1.26 & 6.62 & 0.0368 & 1 & Remarkable \\
\hline $\mathrm{X} 1 \mathrm{X} 2$ & 0.86 & 0.86 & 4.53 & 0.0708 & 1 & \\
\hline $\mathrm{X} 1^{2}$ & 0.22 & 0.22 & 1.17 & 0.3159 & 1 & \\
\hline $\mathrm{X} 2^{2}$ & 2.08 & 2.08 & 10.88 & 0.0131 & 1 & \\
\hline Residual & 1.34 & 0.19 & & & 7 & \\
\hline Degree of dissimilarity & 1.06 & 0.35 & 5.01 & 0.0768 & 3 & Not significant \\
\hline Pure error & 0.28 & 0.07 & & & 4 & \\
\hline Total difference & 7.04 & & & & 12 & \\
\hline
\end{tabular}

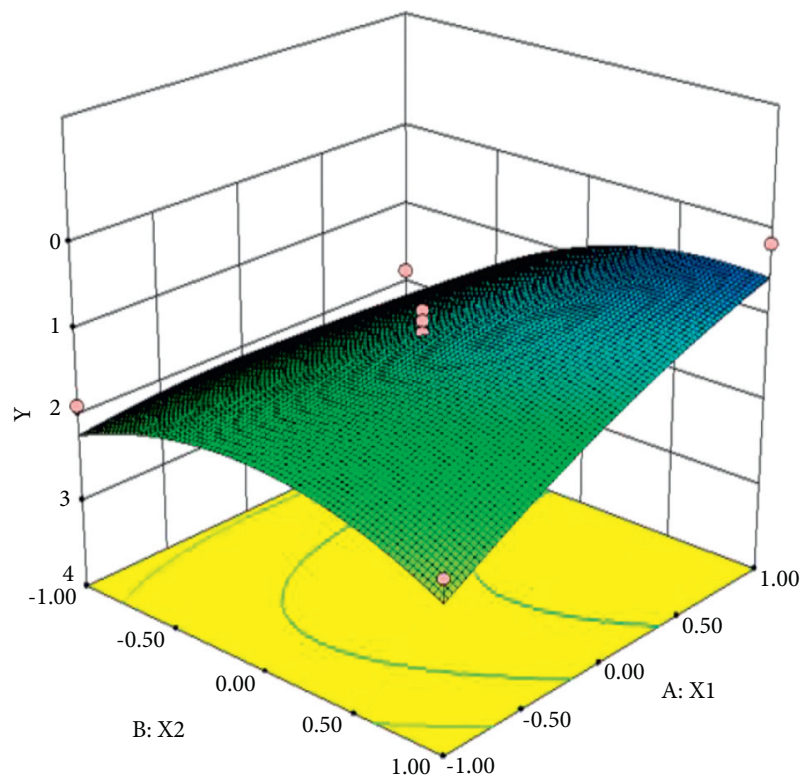

FIGURE 3: Response surface diagram of the effect of methanol ratio and column temperature on resolution.
3.3. Verification Experiment. According to the results of the model analysis, the optimal chromatographic conditions were obtained. The column was Agilent ZORBAX SB-C18, methanol: water $(60: 40)$, the column temperature was $30^{\circ} \mathrm{C}$, the detection wavelength was $275 \mathrm{~nm}$, the flow rate was $1.0 \mathrm{~mL} /$ min, and the injection volume was $10 \mu \mathrm{L}$. Three samples were tested in parallel, and the average chromatographic resolution was 2.30. The measured value was compared with the value predicted by the equation, and the deviation was calculated. The average deviation was $1.30 \%$, and the deviation was small, indicating that the model was effective.

3.4. Study on the Method of "QAMS". According to the chromatographic conditions determined under "3.2," accurately drew $10 \mu \mathrm{L}$ each of the mixed reference solution and test solution under " 2.2 " and injected them into the liquid chromatograph. The results are given in Figures 4 and 5.

3.4.1. Investigation of Linear Relationship. Precisely drew 1, $2,5,10,15$, and $20 \mu \mathrm{L}$ of the mixed reference solution under "2.2," respectively, and performed regression processing on 


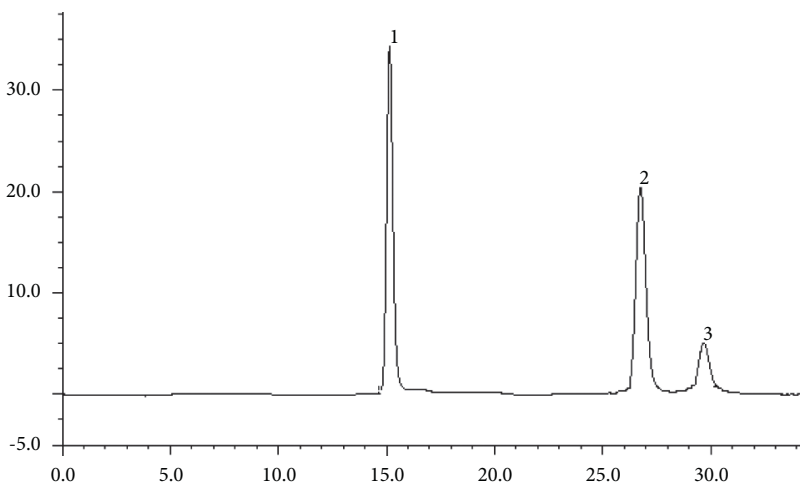

Figure 4: HPLC chromatograms of reference substance. Note: 1, euphorbia factor L3; 2, euphorbia factor L1; 3, euphorbia factor L4.

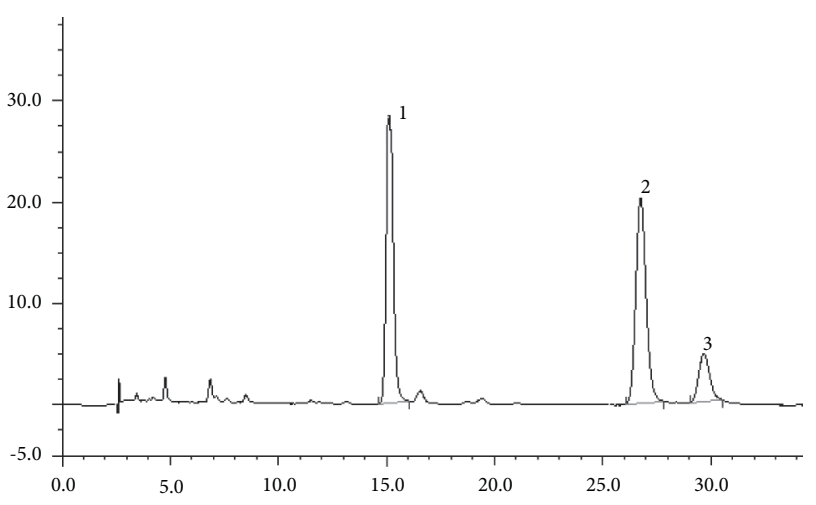

FIGURE 5: HPLC chromatograms of sample. Note: 1, euphorbia factor L3; 2, euphorbia factor L1; 3, euphorbia factor L4.

the peak area integral value based on the injection volume. The results show that each component was within the corresponding range, and the linear relationship was good. The results are given in Table 4 .

3.4.2. Stability Test. Took the same test product solution under "2.2," injected samples after 0, 2, 8, 12, 24, and 36 hours, respectively, recorded the peak area, and calculated the RSD for each component. The RSD values of euphorbia factor L1, euphorbia factor L3, and euphorbia factor L4 were $1.14 \%$, $0.92 \%$, and $1.08 \%$, respectively; all were less than $2.0 \%$. The results showed that the test solution was basically stable after being placed for $36 \mathrm{~h}$ under experimental conditions.

3.4.3. Repeatability Test. Took the same batch of euphorbia factor medicinal materials to prepare 6 test product solutions according to the test product preparation method under "2.2," determined according to law, and the RSD contents of euphorbia factor L1, euphorbia factor L3, and euphorbia factor L4 were $0.99 \%, 1.02 \%$, and $1.13 \%$; all were less than $2.0 \%$, indicating that the method has good repeatability.

3.4.4. Precision Test. Took the mixed reference solution under " 2.2 " to repeatedly inject for 6 times, measured the peak area, and calculated the RSD. The RSD values of
TABLE 4: Standard curve of euphorbia factor L1, L3, and L4.

\begin{tabular}{lccc}
\hline Compound & Standard curve & $r$ & $\begin{array}{c}\text { Linear range } \\
(\mu \mathrm{g})\end{array}$ \\
\hline $\begin{array}{l}\text { Euphorbia factor } \\
\text { L1 }\end{array}$ & $Y=1244.6 X+10.218$ & 0.9999 & $0.1008-2.016$ \\
\hline $\begin{array}{l}\text { Euphorbia factor } \\
\text { L3 }\end{array}$ & $Y=1516.8 X-12.176$ & 0.9998 & $0.1005-2.010$ \\
\hline $\begin{array}{l}\text { Euphorbia factor } \\
\text { L4 }\end{array}$ & $Y=597.4 X+11.613$ & 0.9999 & $0.1505-3.010$ \\
\hline
\end{tabular}

euphorbia factor L1, euphorbia factor L3, and euphorbia factor L4 are $1.24 \%, 1.08 \%$, and $1.15 \%$, respectively; all were less than $2.0 \%$, indicating that the precision of the instrument is good.

3.4.5. Sample Recovery Test. Took an appropriate amount of 6 parts of calamansi powder with known content, each about $0.5 \mathrm{~g}$, accurately weighed them, added the same amount of mixed reference solution, respectively, and prepared the test solution according to the method under " 2.2 ," determined according to law, and the recovery rate was calculated. The average recovery rates of euphorbia factor L1, euphorbia factor L3, and euphorbia factor L4 were 100.14\%, 99.97\%, and $99.68 \%$, respectively, and the RSD values were $1.02 \%$, $1.06 \%$, and $0.98 \%$, respectively; all were less than $2.0 \%$, indicating that the accuracy of this method is good.

$$
\text { Recovery }(\%)=\frac{(A-B)}{C} \times 100 \% \text {, }
$$

where $A$ is the measured value, $B$ is the measured component contained in the test sample, and $C$ is the amount of control sample added.

\subsection{Determination of Relative Correction Factor}

3.5.1. Calculation of Relative Correction Factor. According to the chromatographic conditions determined under "3.2," accurately drew the mixed reference solution prepared under " 2.2 " and injected $1,2,5,10,15$, and $20 \mu \mathrm{L}$ to determine the peak area of each component. Took the euphorbia factor L1 as the internal standard to calculate the relative correction factors between euphorbia factor L3, euphorbia factor L4, and euphorbia factor L1 according to the relative correction factor calculation formula, namely, $\mathrm{fsi}=\mathrm{fs} / \mathrm{fi}=(\mathrm{As} / \mathrm{Cs}) /(\mathrm{Ai} / \mathrm{Ci})$ (where As is the peak area of the internal reference, $\mathrm{Ai}$ is the peak area of other components, $\mathrm{Cs}$ is the internal reference concentration, and $\mathrm{Ci}$ is the concentration of other components) [23-25], as given in Table 5.

\subsubsection{Reproducibility Investigation of Relative Correction} Factor. Effect of different brands of chromatographic columns on $f$ : according to the HPLC chromatographic conditions determined under "3.2," accurately drew the mixed reference solution $10 \mu \mathrm{L}$ prepared under " 2.2 " and investigated the effects of three different brands of chromatographic columns on the relative correction factors of each 
TABLE 5: Relative correction factor of two components.

\begin{tabular}{lcr}
\hline Injection volume $(\mu \mathrm{L})$ & $f_{\mathrm{L} 3 / \mathrm{L} 1}$ & $f_{\mathrm{L} 4 / \mathrm{L} 1}$ \\
\hline 1 & 0.992 & 1.802 \\
2 & 0.978 & 1.791 \\
5 & 0.994 & 1.806 \\
10 & 0.971 & 1.835 \\
15 & 0.986 & 1.794 \\
20 & 0.989 & 1.753 \\
Average & 0.985 & 1.797 \\
RSD\% & 0.90 & 1.48 \\
\hline
\end{tabular}

TABLE 6: Effect of different brands of chromatographic columns on $\mathrm{f}$.

\begin{tabular}{lcc}
\hline Chromatographic columns & $f_{\mathrm{L} 3 / \mathrm{L} 1}$ & $f_{\mathrm{L} 4 / \mathrm{L} 1}$ \\
\hline ZORBAX SB-C18 & 0.991 & 1.802 \\
GL InertSustain C18 & 0.978 & 1.813 \\
Sagix Copsil C18 & 0.984 & 1.798 \\
Average & 0.984 & 1.804 \\
RSD\% & 0.66 & 0.43 \\
\hline
\end{tabular}

TABLE 7: Effect of different brands of HPLC instrument on $f$.

\begin{tabular}{lcc}
\hline Instrument & $f_{\mathrm{L} 3 / \mathrm{L} 1}$ & $f_{\mathrm{L} 4 / \mathrm{L} 1}$ \\
\hline UltiMate 3000 & 0.980 & 1.807 \\
Waters 2695 & 0.979 & 1.818 \\
Agilent 1290 Infinity II & 0.992 & 1.810 \\
Average & 0.984 & 1.812 \\
RSD\% & 0.74 & 0.31 \\
\hline
\end{tabular}

component by Agilent HPLC [26]. The results are given in Table 6, which shows that the relative correction factors obtained by different chromatographic columns are basically the same.

Effect of different brands of HPLC instrument on $f$ : according to the HPLC chromatographic conditions determined under " 3.2 ," accurately drew the mixed reference solution $10 \mu \mathrm{L}$ prepared under " 2.2 " and investigated the effects of 3 different brands HPLC instrument of UltiMate 3000, Waters 2695, and Agilent 1290 Infinity II on the relative correction factor. The results are given in Table 7 . It shows that the relative correction factors obtained by using different brands of HPLC instrument are basically the same.

3.5.3. Positioning of Chromatographic Peaks. It is a problem that must be solved in this method to quickly and accurately identify the other two components in medicinal materials when only one reference substance is used [27,28]. Introduce the relative retention value of each component to be tested as the positioning parameter and investigate the repeatability under the conditions of different brands of instruments and different specifications of chromatographic columns [29]. According to the HPLC chromatographic conditions determined under "3.2," accurately drew the mixed reference solution $10 \mu \mathrm{L}$ prepared under " 2.2 " and determined the relative retention time of the internal reference euphorbia factor L1. According to the relative retention time, the accurate peak positions of the target peak euphorbia factor L3 and euphorbia factor L 4 can be correctly judged, the relative retention time error is controlled within $5 \%$, and the results are given in Table 8 . It can be seen from Table 8 that the RSD values were all less than $2 \%$, indicating that the relative retention time is used to locate the chromatographic peak and the method is feasible.

3.6. Comparison of the Results of the QAMS and the External Standard. Took different batches of medicinal materials, used the external standard method and the QAMS method to calculate the amount of euphorbia factor L1, euphorbia factor L3, and euphorbia factor L4 in Euphorbia lathyris L., and the results obtained by the two methods were compared to verify the accuracy of the QAMS method for the content evaluation of multiindex ingredients in Euphorbia lathyris L. The results are given in Table 9, which suggested that the results measured by the QAMS method and the external standard method of the euphorbia factor L1, euphorbia factor L3, and euphorbia factor L4 were basically the same, and the SD value of QAMS is small, indicating that the established QAMS method was credible. 
TABLE 8: Relative retention time measured by different brands of instruments and chromatographic columns.

\begin{tabular}{lccc}
\hline Instrument & Chromatographic columns & \multicolumn{2}{c}{$\begin{array}{c}\text { Relative retention time } \\
\text { Euphorbia factor L3/euphorbia factor L1 }\end{array}$} \\
& & 0.5591 & Euphorbia factor L4/euphorbia factor L1 \\
\hline UltiMate 3000 & Sagix Copsil C18 & 0.5671 & 1.1251 \\
UltiMate 3000 & ZORBAX SB-C18 & 0.5904 & 1.1302 \\
Waters 2695 & Sagix Copsil C18 & 0.5681 & 1.1260 \\
Waters 2695 & GL InertSustain C18 & 0.5802 & 1.1311 \\
Agilent 1290 Infinity II & ZORBAX SB-C18 & 0.5719 & 1.1265 \\
Agilent 1290 Infinity II & GL InertSustain C18 & 0.5728 & 1.1235 \\
Average & & 1.92 & 1.1271 \\
RSD\% & & & 0.26 \\
\hline
\end{tabular}

TABLE 9: Determination of euphorbia factor L1, euphorbia factor L3, and euphorbia factor L4 in Euphorbia lathyris L.

\begin{tabular}{|c|c|c|c|c|c|}
\hline \multirow[b]{2}{*}{ Batches } & \multirow{2}{*}{$\begin{array}{l}\text { Euphorbia factor L1 (\%) } \\
(\text { mean } \pm \text { SD) }\end{array}$} & \multicolumn{2}{|c|}{ Euphorbia factor L3 (\%) } & \multicolumn{2}{|c|}{ Euphorbia factor L4 (\%) } \\
\hline & & $\begin{array}{c}\text { QAMS } \\
(\text { mean } \pm S D)\end{array}$ & $\begin{array}{l}\text { External standard method } \\
(\text { mean } \pm S D)\end{array}$ & $\begin{array}{c}\text { QAMS } \\
(\text { mean } \pm S D)\end{array}$ & $\begin{array}{c}\text { External standard method } \\
(\text { mean } \pm S D)\end{array}$ \\
\hline $20200405(n=3)$ & $0.2021 \pm 0.0079$ & $0.2901 \pm 0.0056$ & $0.2899 \pm 0.0109$ & $0.1675 \pm 0.0083$ & $0.1676 \pm 0.0107$ \\
\hline $20200419(n=3)$ & $0.3232 \pm 0.0102$ & $0.2684 \pm 0.0067$ & $0.2687 \pm 0.0070$ & $0.1743 \pm 0.0068$ & 0.0078 \\
\hline $20200602(n=3)$ & $0.2682 \pm 0.0072$ & $0.2767 \pm 0.0085$ & $0.2768 \pm 0.0089$ & $0.1834 \pm 0.0087$ & $=0.0093$ \\
\hline $20200617(n=3)$ & $0.1355 \pm 0.0087$ & $0.1897 \pm 0.0086$ & $0.1899 \pm 0.0088$ & $0.1737 \pm 0.0102$ & $0.1738 \pm 0.0098$ \\
\hline $20200912(n=3)$ & $0.2682 \pm 0.0110$ & $0.3322 \pm 0.0104$ & $0.3320 \pm 0.0097$ & $0.2011 \pm 0.0096$ & $0.2009 \pm 0.0106$ \\
\hline $20200926(n=3)$ & $0.3127 \pm 0.0067$ & $0.2798 \pm 0.0113$ & $0.2797 \pm 0.0109$ & $0.1932 \pm 0.0078$ & $0.1930 \pm 0.0093$ \\
\hline $20201218(n=3)$ & $0.2356 \pm 0.0093$ & $0.2669 \pm 0.0098$ & $0.2667 \pm 0.0111$ & $0.1736 \pm 0.0069$ & $0.1735 \pm 0.0076$ \\
\hline $10101222(n=3)$ & $0.3823 \pm 0.0095$ & $0.2638 \pm 0.0087$ & $0.2637 \pm 0.0094$ & $0.1865 \pm 0.0109$ & $0.1866 \pm 0.0099$ \\
\hline
\end{tabular}

\section{Discussion}

The content of euphorbia factor L1, euphorbia factor L3, and euphorbia factor L4 is relatively high in Euphorbia lathyris L., and its anticancer biological activity is strong, so it is of great significance to select diterpenoids as the internal quality evaluation indexes for the quality control of $\mathbf{E u}$ phorbia lathyris L. In this experiment, based on the QbD to design and screening key analysis parameters, a QAMS method for diterpenoids was established. At the same time, the durability of the instrument and chromatographic column was investigated [30-32]. The results show that the experimentally established relative correction factor $f$ has good reproducibility, and there is no significant difference between the results obtained by the QAMS method and the external standard method. The QAMS method established in this experiment has high reproducibility, stability, and reliability when determining the amount of euphorbia factor L1, euphorbia factor L3, and euphorbia factor L4, which enriches the quality evaluation method of the content of Euphorbia lathyris L., and has provided a more sufficient reference and basis for the promotion and application of QAMS technology in the quality control of traditional Chinese medicine. QAMS is expected to solve the problems of shortage of reference materials and high testing costs in the multiindex quality evaluation of traditional Chinese medicine $[33,34]$.

\section{Data Availability}

The data used to support the findings of this study are available from the corresponding author upon request.

\section{Conflicts of Interest}

The authors declare that there are no conflicts of interest.

\section{Acknowledgments}

This research was funded by the Natural Science Research Foundation of the Department of Education of Anhui Province (No. KJ2020A0789), Anhui provincial-level quality engineering project: (2020jyxm0790, 2020zyrc077, 2011rcpys01, gxbjZD2021089); school-level grassroots teaching and research office demonstration project of Anhui Xinhua University (2019jyssfx02).

\section{References}

[1] R. Mehta, J. Teckoe, C. Schoener, S. Workentine, D. Ferrizzi, and A. Rajabi-Siahboomi, "Uncovering interaction by QbD in optimization of stability-indicating HPLC method for simultaneous estimation of low-dose aspirin and lansoprazole," AAPS Pharmscitech, vol. 17, no. 6, pp. 1366-1375, 2016.

[2] I. Harbi, B. Aljaeid, K. M. El-Say, and A. S. Zidan, "Investigation of the effects of materials and dry granulation process on the mirabegron tablet by integrated QbD approach with multivariate analysis," AAPS Pharmscitech, vol. 17, no. 6, pp. 1404-1420, 2016.

[3] K. Bhise, S. K. Kashaw, S. Sau, and A. K. Iyer, "Nanostructured lipid carriers employing polyphenols as promising anticancer agents: quality by design (QbD) approach," International Journal of Pharmaceutics, vol. 526, no. 1-2, pp. 506-515, 2017.

[4] J. T. Ning, J. M. Sun, Z. M. Wang, X. W. Zhang, and W. Y. Zhang, "Design and in vitro release study of valsartan bilayer tablets based on quality by design (QbD) concept," 
Chinese Pharmaceutical Journal, vol. 56, no. 03, pp. 210-217, 2021.

[5] X. M. Wang, Z. Y. Zhao, H. Wang, and H. J. Tian, "Determination of five heavy metals in soil by inductively coupled plasma atomic emission spectrometry based on analytical method quality source design," Physical Testing and Chemical Analysis (Part B:Chemical Analysis), vol. 56, no. 12, pp. 1313-1319, 2020.

[6] Y. Tang, A. J. Zhang, S. Li, H. M. Zhu, J. Z. Mao, and L. Y. Yu, "Study on preparation technology and physical fingerprint of qiwei chanshen granules based on QbD," Journal of Chinese Medicinal Materials, vol. 44, no. 01, pp. 146-152, 2021.

[7] Y. K. Bao, Y. Guo, S. S. Kang et al., "Simultaneous determination of 4 chemical constituents in garidi- 5 pill by QAMS method," Environmental Chemistry, vol. 39, no. 12, pp. 3585-3587, 2020.

[8] G. Kuang, J. Zhou, M. Yao et al., "Systematic study on QAMS method for simultaneous determination of triterpenoid saponins in ilex pubescens by HPLC and UPLC," Analytical Methods, vol. 7, no. 16, pp. 6579-6587, 2015.

[9] D. W. Li, M. Zhu, Y. D. Shao, Z. Shen, C. C. Weng, and W. D. Yan, "Determination and quality evaluation of green tea extracts through qualitative and quantitative analysis of multi-components by single marker (QAMS)," Food Chemistry, vol. 197, pp. 1112-1120, 2016.

[10] L. Cui, Y. Zhang, W. Shao, and D. Gao, "Analysis of the HPLC fingerprint and QAMS from Pyrrosia species," Industrial Crops and Products, vol. 85, pp. 29-37, 2016.

[11] Y. T. Ouyang, Z. B. Tan, and L. M. Chen, "Simultaneous determination of three phenolic acids in Artemisia Japonica by QAMS," Pharmacy Today, vol. 31, no. 01, pp. 23-26, 2021.

[12] J. Yao, X. G. Sun, R. Dong, J. H. Xie, Y. L. Wang, and X. N. Yang, "Simultaneous quantitative analyses of six components in Astragalus membranaceus based on HPLC$\mathrm{CAD}$ and quantitative analysis of multi-components with a single-marker," Acta Pharmaceutica Sinica, vol. 56, no. 02, pp. 557-564, 2021.

[13] P. H. Niao, L. J. Weng, S. L. Liu, and D. Geng, "Research progress on chemical constituents of Euphorbia Lathylris and its phamacological activities," Modern Chinese Medicine, vol. 22, no. 2, pp. 296-304, 2020.

[14] S. S. Yang, Separation of Anticancer Compounds from the Euphorbia Lathyris and its Pharmacological Research, Tianjin University, Tianjin, China, 2016.

[15] J. S. Dong, J. F. Zhao, R. T. Chen et al., "Effects of semen Euphorbiae Lathyridis on the expression of livinprotein and TNF- $\alpha$ in cancer tissues of nude mouse model of renal cancer," Oncology Progress, vol. 15, no. 6, pp. 631-633, 2017.

[16] Q. Tian, Active Ingredient Analysis and Extraction Process Optimization in Euphorbia Lathyris L, Shanxi University, Taiyuan, China, 2015.

[17] Y. H. Li, Y. M. Peng, Z. Q. Wang et al., "Alcohol extraction process for feifufang granules based on the quality-by-design concept," Hunan Journal of Traditional Chinese Medicine, vol. 37, no. 01, pp. 155-159, 2021.

[18] M. T. Lu, J. M. Sun, and C. C. Fang, "Design and optimization of preparation process of paracetamol bi-release bilayer tablets based on QbD concept," Chinese Journal of Hospital Pharmacy, vol. 40, no. 24, pp. 2535-2539, 2020.

[19] M. T. Li, Q. Liu, Y. Q. Zhang, M. D. Ye, and W. X. Wang, "Preparation and characterization of ternary indomethacin solid dispersion based on quality by design (QbD) concept," Chinese Pharmaceutical Journal, vol. 55, no. 17, pp. 1450$1455,2020$.
[20] J. L. Jiang, X. X. Shan, and L. Sun, “Application of a quality by design approach to optimize separation of alkaloids in Sophora flavescens," Journal of Tianjin University (Science and Technology), vol. 53, no. 11, pp. 1204-1210, 2020.

[21] Z. Q. Chen, F. Zhao, W. Yuan et al., "Multi-index optimization of alcohol extraction and water precipitation processes of shenmai injection based on quality by design concept," Chinese Traditional and Herbal Drugs, vol. 51, no. 17, pp. 4433-4441, 2020.

[22] Y. H. He, H. X. Shi, B. S. Diao, and L. Yang, "Extraction process of shanshenyin based on QbD concept," China Pharmaceuticals, vol. 29, no. 15, pp. 28-32, 2020.

[23] H. Y. Xu, C. X. He, S. X. Luo, Z. Q. Yang, H. B. He, and Y. M. He, "Determination of five triterpenes in centellae herba by a combinative method of HPLC fingerprint and quantitative analysis of multi-components by single marker," Chinese Pharmaceutical Journal, vol. 56, no. 03, pp. 181-188, 2021.

[24] Y. X. Liu, C. P. Feng, L. L. Liu, Q. F. Mao, Y. M. Qiu, and L. Y. Peng, "Simultaneous determination of 8 components in erzhi pills by QAMS method," Chinese Journal of Pharmaceutical Analysis, vol. 41, no. 02, pp. 210-218, 2021.

[25] J. Feng, L. Chai, M. S. Chen, J. T. Yuvan, and B. M. Liu, "Application of fingerprint combined with QAMS in quality evaluation of amomum paratsao-ko," Chinese Traditional and Herbal Drugs, vol. 52, no. 03, pp. 852-856, 2021.

[26] L. G. Tong, Y. Y. Liu, R. Y. Wang et al., "Simultaneous determination of the contents of 6 components in fuzheng guben granules by QAMS," China Pharmacy, vol. 32, no. 02, pp. 225-230, 2021.

[27] Y. Huang, F. Y. Dong, C. Y. Li, and D. Q. Wang, "Simultaneous quantitative determination of 10 chemical constituents in radix isatidis by QAMS method," Chinese Traditional and Herbal Drugs, vol. 52, no. 03, pp. 845-851, 2021.

[28] L. Huang, C. Y. Yao, Y. Liang et al., "Determination of three non-alkaloids from sophorae tonkinensis radix et rhizoma with quantitative analysis of multi-components by single marker," Modern Chinese Medicine, vol. 22, no. 12, pp. 2015-2020, 2020.

[29] L. Duan, Q. C. Zhu, E. Wang, and Y. C. Sun, "Determination of the contents of 5 components in Psoralea corylifolia by QAMS," Northwest Pharmaceutical Journal, vol. 36, no. 01, pp. 10-14, 2021.

[30] Z. G. Zhao, J. H. Yao, J. N. Wang, and Y. Y. Zhai, "Imultaneous determination of the contents of 7 components in zhishushi lotion by QAMS," Northwest Pharmaceutical Journal, vol. 36, no. 01, pp. 14-19, 2021.

[31] B. F. Zhang, J. Wang, and H. Y. Chen, "Determination of 7 components in buxiqi oral liquid by QAMS," Northwest Pharmaceutical Journal, vol. 36, no. 01, pp. 29-34, 2021.

[32] X. M. Xu, X. Y. Wu, H. Yi et al., "Determination of 6 components in tibetan medicine berberis cortex with quantitative analysis of multi-components by single marker," Chinese Journal of New Drugs, vol. 29, no. 24, pp. 2852-2858, 2020.

[33] D. J. Liu, L. He, M. M. Fan, H. W. Tao, and Y. N. Mu, "Quantitative determination of seven components in qianlieping capsule by HPLC-QAMS," Practical Pharmacy And Clinical Remedies, vol. 23, no. 12, pp. 1119-1125, 2020.

[34] Y. H. Huang, Y. F. Yang, and Y. Chen, "Qulity control for 7 components in bushen fangchuan tablets by QAMS," Northwest Pharmaceutical Journal, vol. 35, no. 05, pp. 653658, 2020. 